\title{
Preliminary Study on Workshop Facilitation for IoT Innovation as Industry-University Collaboration PLM Program for Small and Medium sized Enterprises
}

\author{
Satoshi Goto ${ }^{1,2}$, Osamu Yoshie ${ }^{1}$, Shigeru Fujimura ${ }^{1}$, and Kin’ya Tamaki ${ }^{3}$ \\ ${ }^{1}$ Graduate School of Information, Production and Systems, Waseda University, Japan \\ ${ }^{2}$ Business Transformation Management, PTC Japan Co. Ltd., Japan \\ ${ }^{3}$ Human Innovation Research Center, Aoyama Gakuin University, Japan \\ satoshi-goto@fuji.waseda.jp, yoshie@waseda.jp, \\ fujimura@waseda.jp, kinya.tamaki@gmail.com
}

\begin{abstract}
The global manufacturing business is in the new era of industrial revolution based on digital data across the whole business processes. Internet of Things (IoT) is one of extremely high expected technologies. They contribute product lifecycle management (PLM) process, such as remote monitoring of field service and predictive quality reliability engineering design. However, it assumes significant difficulties for small and medium sized enterprises (SME) to launch rapidly IoT solution for their business efficiency or strategic differentiation. Thus, this paper proposes a pragmatic IoT Innovation workshop approach for such SMEs' employees. This is as an industry-university collaboration PLM educational program utilizing both design thinking business methodology and commercial IoT application technology hands-on. It also introduces outcomes as a preliminary phase for empirical study on this workshop approach that deployed for a local city in the Far East area.
\end{abstract}

Keywords: Internet of Things, Workshop Facilitation, Industry-University Collaboration, Design Thinking, Product Lifecycle Management, Educational and Training Approach

\section{Introduction}

The global and distributed industrial world has been producing various business trends and case studies in terms of product lifecycle management (PLM) process in the past decade [1]. In addition to such PLM approach, nowadays, a large business operating on a global scale would be aiming for the realization of smart connected product and smart factory where IoT technology is applied in industry while investing capital on a grand scale [2].

On the other hand, what is the current situation of small to medium enterprises (SME)? They are limited due to having small scale and range of business. Securements of capital or human resources are also not always enough. However, in order 
for the industries in national country to continue developing, the contribution from SMEs making use of a widely spread regional network is essential. For example, the German SME comprises $99.6 \%$ of all enterprises in the country [3].

Based on such so-called fourth industrial revolution taking place, it is significantly meaningful for SME's whole product lifecycle to conduct investigative research into the strategic direction relating to information communication technology (ICT).

At present the authors are working on empirical research and business development via stakeholders' consensus building methods in the creation of vision and strategy [4]. This includes a study of IoT enabled commercial PLM application software for supporting IoT functionality which is installed on the main product of a manufacturing business [5]. We have been also working on research relating to the methods of agreement formation which can efficiently conceive a new business model in response to the product lifecycle process of discrete manufactures. This is to develop engineering and business management education program regarding PLM system as a part of industry-university collaboration [6].

With the background as described as above, this paper reports on a result from trial evaluation of "business initiative workshop on internet of things (IoT)" that we developed. Chapter 2 outlines the basic structure of the workshop developed in this research, expected types of participants as well as the technology which will be experienced. Chapter 3 reports the result of the preliminary trial implemented by the participating monitors in respect of the workshop methodology developed by our research team. Then in Chapter 4 the purpose and efficacy of the business modelling method called "design thinking [7]" applied in this workshop will be discussed. At the same time it discusses existing issues relating to industry-university collaboration.

In the final chapter, Chapter 5, it concludes relating to industry-university collaboration program for the promotion of new industries in a local area while concluding this research.

\section{Basic Concept}

\subsection{Configuration of Workshop Agenda}

This workshop is designed for employees and managers who are working at the local SME. It aims to be a short term and intensive human resources developmental lecture. This is a unique three discussion package, which are 1) business modeling, 2) technology hands-on and 3) field work out of the workshop seminar room. It configures for seven hours per a day and three consecutive days in total.

Day 1 - Value Identification. This workshop delivers as a group discussion format. It utilizes design thinking business methodology. With this, the participants are made aware of insights relating to IoT businesses. Finally, each group shall draw up a hypothesis of a new business model idea to tackle in the future. 
Day 2 - Technology Experience. It experiences commercial ICT applications relating to the latest IoT and Augmented Reality (AR). This allows the participants to realize a practical work on computers. With this, it can validate out whether or not the imaginary new business model created on day 1 can be technologically supported with such ICT technologies.

Day 3 - Value Planning. This whole day is a field work exploring the local town where the participants work at. The participants visit that area in person. There are also opportunities for them to directly interview the local businesses people regarding their business strategy or stance so that the participants can understand the issues faced by the area. Participants can finally define a practical business model journey to improve the specific points of view considering with the contents of Day 1 and 2.

\subsection{Assumed Profile of the Participants}

The following is the expected profile of participants in this workshop. The premise is that the participants should be working at local SME. For example, middle class workers in local SME with the following experience or jobs was assumed to be a potential participant.

- A proprietor, successor or head of department

- A leading core human resource who is a future potential executive

- A specialist with interest in new business development and strategy setting

- A system engineer on business systems; e.g., CAD, PLM, ERP and CRM systems

- A middle manager interested in latest technology of the world such as IoT and AR

\subsection{Opportunity to Experience of State-the-Arts Technologies}

In addition to group discussions, it provides the opportunity to get real experience of state-of-the-arts technology solutions and application platforms such as IoT, AR, CAD and PLM application software that the manufacturing industries are working on. A hands-on session will be provided to the participants.

\section{Case Study as a Preliminary Trial Workshop}

In order to proof of the workshop concept, a preliminary trial workshop was implemented in city K. The city is an industrial area since the latter half of 19th century. It has been leading business region of manufactured metals, cars and energy industry as the place of origin of Japan's modern industry. However, looking back over the past 15 years, it's hard to say that there has been progress in economy of manufacturing activities. With the arrival of super aging society, many local industries would be remaining on a plateau. Local SME particularly fear serious business results downturn. In other words, it's thought that strengthening the imagination of new business planning and conception of new technological development while appreciating the full lifecycle of a product or a service is something that is needed urgently. 
In such industry background, with area $\mathrm{W}$ in city $\mathrm{K}$ with a historical and industrial backdrop, the trial workshop was held. Inviting monitor participants, it deployed the verification and evaluation of the workshop concept. The implemented agenda and results were as follows. By the way, the author's university is located in area W.

\subsection{Date and Time}

- Date: 14, 15 and 16 September, 2016 (consecutive three days)

- Time: from 10:00 a.m. through 5:00 p.m. (net 6 hours except for break time)

\subsection{Venue and Place}

- Workshop room 1: A classroom at university campus of our research team

- Workshop room 2: A meeting room at local community center in area W

- Field work area: Four locations (shopping street, historical business grade area, fish processing company and fruit and vegetable market)

\subsection{Member}

- 6 Workshop Participants - residing in city K (as monitor participants)

- 1 Workshop Facilitator - experienced in this industry for 30 years

- 1 Application Specialist - operating experience of IoT and AR technologies

\subsection{Technology}

The information communication technology (ICT) used in this trial workshop was the ThingWorx as an IoT development platform and Vuforia as augmented reality software. Both were produced by PTC Inc. which is one of the global leaders providing the market with commercial IoT and AR technology and solutions [8].

Note: As this was the first preliminary trial, both CAD and PLM applications were not prepared yet. We are planning to implement them as the next trial in late 2017.

\subsection{Specific Session Streams}

The following shows the actual agenda structure, timetable and content implemented over a total of three days. The intensive workshop over three days was formed of a total of 20 independent sessions. The following Table 1, 2 and 3 are introduced the session streams:

Day 1: Hypotheses Definition on IoT Innovation;

Day 2: User Experience with State-of-the-Arts ICT Technologies;

Day 3: Conception of New Business Strategy through Field Observations. 
Table 1.

Day 1: Hypotheses Definition on IoT Innovation

\begin{tabular}{|c|c|}
\hline $\begin{array}{l}\text { Session \#, Topic, } \\
\text { (duration) }\end{array}$ & Session Activity in Day 1 \\
\hline $\begin{array}{l}\text { 1-A, Warming up } \\
\text { (15 min.) }\end{array}$ & $\begin{array}{l}\text { As an ice breaker, each person introduced themselves and shared their thoughts } \\
\text { on their impression of area } \mathrm{W} \text { in city } \mathrm{K} \text {, such as the lifestyle there and the } \\
\text { current status of the region. }\end{array}$ \\
\hline $\begin{array}{l}\text { 1-B, Confirmation } \\
\text { of business topics } \\
\text { (45 min.) }\end{array}$ & $\begin{array}{l}\text { As the start of the workshop, a questionnaire was filled in by the participants in } \\
\text { advance. From this, the participants attempted to hypothesize the direction of } \\
\text { business strategy. }\end{array}$ \\
\hline $\begin{array}{l}\text { 1-C, Specifying } \\
\text { problems to be } \\
\text { solved } \\
\quad(60 \text { min. })\end{array}$ & $\begin{array}{l}\text { The } 26 \text { types of IoT use case [4] used by our research team were categorized } \\
\text { using the " } 2 x 2 \text { matrix" method which is one of the methods for design thinking } \\
\text { [12]. These use cases were shared between participants and whether new ideas } \\
\text { and discoveries popped up was confirmed among the group members. }\end{array}$ \\
\hline $\begin{array}{l}\text { 1-D, Confirmation } \\
\text { of business strategy } \\
\text { (60 min.) }\end{array}$ & $\begin{array}{l}\text { From the above use cases categorized using the } 2 \times 2 \text { method, one that a group } \\
\text { member thought most important use case was specified as a start point, a dis- } \\
\text { cussion was conducted regarding what the original business "objectives" would } \\
\text { be using IoT. By using the design thinking method called "value graph", a } \\
\text { brainstorm took place giving consideration so that group members are not } \\
\text { swayed by pre-conceptions, regarding what purpose of IoT technology would } \\
\text { be used as a mean in businesses. There was a challenge to see whether a new } \\
\text { idea for applying IoT technology may come to mind. }\end{array}$ \\
\hline $\begin{array}{l}\text { 1-E, IoT use case } \\
\text { introduction } \\
\quad \text { (30 min.) }\end{array}$ & $\begin{array}{l}\text { The facilitator presented significant IoT business case studies which are already } \\
\text { being developed in the world. These aim to be hints for the participants in } \\
\text { conceiving new businesses in the future. }\end{array}$ \\
\hline $\begin{array}{l}\text { 1-F, Customer value } \\
\text { chain analysis } \\
\text { (60 min.) }\end{array}$ & $\begin{array}{l}\text { "CVCA: Customer Value Chain Analysis [9]” method was used and based on } \\
\text { an imaginary business hypothesized in 1-B, the spread of value chain from a } \\
\text { client's point of view was analyzed. From this, a discussion was further deep- } \\
\text { ened to be about who the true final customer is, what the correlation status } \\
\text { between related cooperating business and one's own company and whether } \\
\text { value chains between in-company organizations are appropriate. }\end{array}$ \\
\hline $\begin{array}{l}\text { 1-G, IoT Proto- } \\
\text { typing } \\
\text { (45 min.) }\end{array}$ & $\begin{array}{l}\text { Participants made to specify three places out of the customer value chain dia- } \\
\text { gram drawn up in } 1-\mathrm{F} \text { in which business improvement or benefit of differentia- } \\
\text { tion may be obtained by applying IoT application. IoT application's screen } \\
\text { image to be drawn in those places was pseudo-designed on sketch book. In } \\
\text { other words, this was a "paper prototyping" session. }\end{array}$ \\
\hline $\begin{array}{c}\text { 1-H, Group Presen- } \\
\text { tation } \\
\text { (45 min.) }\end{array}$ & $\begin{array}{l}\text { In order to explain the things which have been discussed in the day, a 5-minute } \\
\text { presentation was given by each group. The imaginary local business, its busi- } \\
\text { ness issues, measures which should be tackled as well as the control of IoT } \\
\text { application thought to be needed as well as their benefits were presented. Final- } \\
\text { ly, the opinions of all the participants were shared in a Q\&A session. }\end{array}$ \\
\hline
\end{tabular}

Table 2.

Day 2: User Experience with State-of-the-Arts ICT Technologies

\begin{tabular}{cl}
$\begin{array}{c}\text { Session \#, Topic, } \\
\text { (duration) }\end{array}$ & Session Activity in Day 2 \\
\hline $\begin{array}{c}\text { 2-A, Review of the } \\
\text { first day }\end{array}$ & $\begin{array}{l}\text { All the steps from day 1 implemented the day before were reviewed by all } \\
\text { participants and the details of work for day 2 were shared and everyone moti- } \\
\text { vated themselves. }\end{array}$ \\
$\begin{array}{ll}\text { 2-B, Hypothesis } \\
\text { creation of daily }\end{array}$ & $\begin{array}{l}\text { The imaginary business conceived in the previous day's discussions was consid- } \\
\text { ered in order to share among everyone the topics which may crop up on a day- }\end{array}$
\end{tabular}


topics in business to-day running of the business based on keywords (three per person) provided (60 min.) by the participants. With this, participants could be made aware constantly of how the IoT applications shown in this second day can become a solving procedure for some business issues.

Starting with a lecture on the summary of ThingWorx functionality, practical

2-C, Experience controlling was experienced of commercially available IoT platforms such as

controls in commer- the specific ThingWorx' screen operations, data import of pseudo sensor data cially available and settings on the screen display as well as remote controls. In the latter half, IoT/AR application each participant used their own smart phones as the AR device for Vuforia development envi- which is PTC's AR platform and the code for AR which had been prepared in ronment advance as workshop materials was given out. With this the participants con(210 min.) firmed the new possibilities for IoT solution when AR technology is incorporated into IoT.

Questions and answers were exchanged between the participants and facilitator 2-D, Q\&A session relating to the technological functionality of ThingWorx or Vuforia for which after operating real operation was experienced. In addition, a free debate was conducted beexperience tween the participants regarding how this technology can play a part in the (30 min.) innovation for future regional improvement and in resolving issues in SME businesses.

The participants went outside of the workshop room (indoor) on day 3. By

2-E, Explanation in realizing fieldwork in which a practical opportunity which is as specific as advance on the possible regarding area $\mathrm{W}$ in city $\mathrm{K}$, a plan was established to continue the area progression of day 3 search. For this a study to gain prior knowledge regarding the area $\mathrm{W}$ is essen(30 min.) tial. Specifically, the monitor participants took it home as homework. The outcomes were to be shared in the group discussion on the following day.

Table 3.

Day 3: Conception of New Business Strategy through Field Observations

\begin{tabular}{|c|c|}
\hline $\begin{array}{l}\text { Session \#, Topic, } \\
\text { (duration) }\end{array}$ & Session Activity in Day 3 \\
\hline $\begin{array}{l}\text { 3-A, Reflection of } \\
\text { day } 1 \text { and } 2 \text { setting } \\
\text { goal of Day } 3 \\
\text { (30 min.) }\end{array}$ & $\begin{array}{l}\text { As the first step in day 3, repeated confirmation was given among the partici- } \\
\text { pants regarding the experience gained of the latest IoT/AR technology as well } \\
\text { as the discussions implemented in the two days' agenda and the points for field } \\
\text { observation on the third day were discussed. This clarified the aims and mean- } \\
\text { ing of the site survey on day } 3 \text { for all participants. The discussion took place in } \\
\text { a waiting room at the railway station closest to area W which is the starting } \\
\text { points of the field survey. }\end{array}$ \\
\hline $\begin{array}{l}\text { 3-B, Field observa- } \\
\text { tion A: local shop- } \\
\text { ping street } \\
\text { (60 min.) }\end{array}$ & $\begin{array}{l}\text { Our real field research started from a railway station. We explored through a } \\
\text { local shopping street in the central part of area W and identify the current state } \\
\text { of shops. For example, this area was successful coal industry until } 50 \text { years ago. } \\
\text { Hence we visited various places relating to that at the time and discussed in } \\
\text { those locations regarding the changes in industry and economy since then as } \\
\text { well as the ups and downs of the manufactured product lifecycle. }\end{array}$ \\
\hline $\begin{array}{l}\text { 3-C, Field observa- } \\
\text { tion B: historically } \\
\text { preserved area } \\
\text { (60 min.) }\end{array}$ & $\begin{array}{l}\text { In area W, there is a famous yard of bridge in Asia. There was a discussion on } \\
\text { the business backdrop at the time of the bridge being constructed (in 1962) and } \\
\text { a further discussion on the pros and cons on the local industry and such product } \\
\text { lifecycle of the construction structure (a bridge). Around the seaside road in } \\
\text { area W, there was a brainstorming of the current topics based on observation of } \\
\text { how the old offices for each business were being preserved. From this, a group } \\
\text { discussion was implemented in respect of the gap between the businesses that } \\
\text { the participants had hypothesized on the first day and the actual situation seen / } \\
\text { heard on site. In particular, for the foreign students residing in area W, how did } \\
\text { this area's situation come across? Moreover, there were discussions using } \\
\text { CVCA defined on the first day in respect of the strategy for supporting people } \\
\text { to stay in area W as well as topics involved in the human resources flow over to } \\
\text { the big cities such as Shanghai, Singapore and Tokyo. }\end{array}$ \\
\hline
\end{tabular}


3-D, Field observation C: Fish processing company

(60 min.)

\section{3-E, Field observa- tion D: Fruit and vegetable market (60 min.)}

3-F, Hypothetical examination of next generation business strategy and a summary of feel observation

(75 min.)

3-G, Final summary (15 min.)
We moved over to area $\mathrm{T}$ on the opposite coast of the port on a ferry boat and visited a historical fish processing company established 100 years ago. We had a lecture by a manager on a specific agenda of the business revolution of the company over the past 100 years. It was a great change through the product lifecycle and a history of global competition. We also identified key issues arising in the business during economic downturn and business transfers as well as how they dealt with.

A research explorer was taken around a local fruit and vegetable market where most of the shops have now closed down. The participants had a discussion regarding the reasons why such a market has disappeared. "Five whys" method was also used to test the specificity of the hypothesis of the underlying cause among participants. Moreover, a vegetable shop that has managed to maintain the business were observed and a discussion conducted among the participants as to why the shop has managed to continue business and also what is required in order to push their business further.

As a summary of the three days' activities, a discussion was conducted with all the participants reflecting the field observation gained throughout the final day on issues, strategies and directions for bringing a new future industrial innovation in area $\mathrm{W}$; the possibility of new products and services and the topics involved in realizing them. The discussion took place in a local public community building at area $\mathrm{W}$ in city $\mathrm{K}$.

All the activities over the three days were reflected upon by all the participants and mutual evaluations were defined as well as proposals about how each would contribute going forward.

\section{Discussion}

\subsection{Key Outcomes of Workshop Content}

This workshop was a short-term intensive session over three days. This trial was characterised by the fact that the following real experiences from three viewpoints were provided to the participants.

Outcome 1. The basic method of "design thinking" was used to provide a place for group work in order to conceive efficiently an innovative hypothesis.

Outcome 2. The innovative hypothesis conceived the actual operating experience for the participants the latest commercial ICT solutions such as IoT and AR. This provided a great opportunity for the participants to experience immediately both value of technology and business strategies at the same timing.

Outcome 3. While getting the participants to keep hold of the business theory and experienced technological theory, a field observation was provided. With this, it provided the ability for participants to conceive more practical products and services for the local community area.

With the above three outcomes incorporated, the short-term intensive business work-shop over three days contributed to enable more sense of achievement to be obtained by the participants and also for the host. There was a possibility that it can efficiently collect voice of local region within a shorter period of time compared to other similar workshops. 
In reality, the implemented trial workshop evaluated to be effective in creating a more realistic approach compared to conventional simple questionnaire survey with the stereotypical analysis results. Furthermore, compared to individual interview style which can only cover a few businesses situation, this workshop was an academic survey method which has a cost-effectiveness and efficient as a value of group discussion.

\subsection{Efficacy of Design Thinking Method Adoption}

In order to efficiently collect opinions and to smoothly obtain the future business concept hypotheses from the participants, this workshop attempted to use a lot of the methods provided in "Innovation dialogue guidebook 2013 [10]". It developed by MECSST (Japan Ministry of Education, Culture, Sports, Science and Technology). The guidebook is developed referring to the design thinking methodology of Stanford d.school. For example organizing topics and measures by dividing into four phenomena based on the " $2 x 2$ matrix [12]" method became a means for participants to start using intellectual imagination. Team work within groups was used in order to tackle issues such as what are the goals for the future and whether new methods and ideas can be synchronized using "value graph". With "CVCA”, it was possible to carefully analyse what the final client or company organization providing the existing value without using the information/data of the relevant stakeholders in the region based on a fixed concept. Those of design thinking methods were used a lot on the first day in this workshop and a lot of idea insights could be provided by the participants.

\subsection{Mutual Benefit as an Industry-University Collaboration}

Currently in various regional cities around Japan, the industrial and academic world is collaborating on various topics as part of the industry-university collaboration programs. Hence social and industrial problems specific to regions are being tackled. However for both parties, it's not necessarily true that they get the same benefit out of the industry-university collaboration program. From the business activity point of view, it goes without saying that practical results contributing to the benefit of businesses are highly in demand. From the point of view of academic researchers, it's probably true that as much as possible of empirical data should be collected for use in research.

Generally, if sufficient merit in participating in this workshop cannot be obtained for the participants from firms cooperating, the workshop format information collecting method does not always work. Therefore, we very much focused on providing the participants practical key two benefits at one time. One is a method for conceiving next generation business strategy in a short period of time; another one is a practical experience of state-of-the-arts commercial ICT technology such as IoT and VR.

\subsection{Voice of Monitor Members - pros and cons.}

The representative feedback from the monitor members of this workshop are shown below. Their feedback will be valuable insights for our next steps to work on this 
workshop methodology development and improvement.

"Firstly I thought that strategy building was to see and feel myself and start being aware for the first time. Hence I understood the importance of questioning everything. To understand something very well is to keep asking questions regarding its cause. Through the workshop today I understood things that I would not have been able to understand just from studying on the desk.” Ms. A (workshop participant)

"It did not only end with the discussions of IoT technology. I could learn about how to distinguish objectives from means in terms of business point of view. Moreover, there haven't been many opportunities to get to know the town that I live in so I am grateful that I have been given this precious opportunity.” Mr. B (workshop participant)

"I experienced things I'd never thought about previously at this workshop. I specialize in computer science so I was thinking, if one does a technical job, and then there is no need to worry about the business. However after three days design thinking, I have lost most of the thoughts I had had previously. I felt that being aware of being customer focused is good work and being a good worker. The most important point is that the local town is different in each place visited. In other words, the businesses to which they are suited to are all different." Mr. C (workshop participant)

"As my 30 years experiences as a facilitator, I saw that this was a unique value as an intensive workshop combining with business modelling and technology hands-on. However, whether people actually working in businesses can participate in this workshop, taking such "three days off" consecutively away from their work needs further consideration regarding the purpose of participation and aims of the activities of the participants.” Mr. D (workshop facilitator)

\section{$5 \quad$ Conclusion and Future Works}

It conducted a preliminary verification with the aim of evaluating the workshop concept. This workshop could be concluded to be a method with a higher satisfaction of participants with usefulness, efficiency in information collection and superiority in cost-effectiveness that cannot be seen in other similar workshops as mentioned the above. However, it is also true that participants of this preliminary trial were still graduate school students or researchers of the research facility that the authors are a part of. Even so, the evaluation from the participants of the practical workshop that we trialled on this occasion was relatively good. Methods and agenda used in this workshop can be concluded to be valuable for future implementation as one of the methods of efficient information collection in considering a regional revival.

Forward looking, it's thought that there is a need to build some sort of industryacademy collaborative facility to instruct the planning / operation of the workshops developed here. In particular, it's thought that developing core people with strong expertise such as facilitators or coordinators in running workshops is quite urgent. By the way, the author's university has been accepting many of international students since 2003 [11]. This allows the local participants to be aware of brand new global 
idea in the future; our research team is currently planning to work on next research and consideration working with the city K's promotion team regarding the challenging topics of local industry-university collaboration PLM program.

Acknowledgements. This work was supported by The Japan Society for the Promotion of Science (JSPS) Grant-in-Aid for Scientific Research (C) No.15K00495 and (B) No.26282088.

\section{References}

1. Bhatt, S., Hseng, F.H., Maranzana, N., Segonds, N.: Scientometric Study of Product Lifecycle Management International Conferences: A Decade Overview. $12^{\text {th }}$ IFIP WG 5.1 International Conference on Product Lifecycle Management (2015)

2. Porter, M.E., Heppelmann, J.E.: How Smart, Connected Products are Transforming Companies. Harvard Business Review93.10, 96-114 (2015)

3. IfM Bonn, http://www.ifm-bonn.org/statistiken/mittelstand-imueberblick/\#accordion=0\&tab=1. Accessed 12 Feb 2017

4. Goto, S., Trolio, E., Yoshie, O., Tamaki, K.: Multi-party Interactive Visioneering Workshop for Smart Connected Products in Global Manufacturing Industry Considering PLM. $13^{\text {th }}$ IFIP WG 5.1 International Conference on Product Lifecycle Management (2016)

5. Goto, S., Yoshie, O., Fujimura, F.: Internet of Things Value for Mechanical Engineers and Evolving Commercial Product Lifecycle Management System. The IEEE International Conference on Industrial Engineering and Engineering Management (2016)

6. Tamaki, K., Park, Y.W. Goto S.: A professional training programme design for global manufacturing strategy: investigations and action project group activities through industry-university cooperation. International Journal of Business Information Systems 18:4, 451-468 (2015)

7. Stanford University Institute of Design, http://dschool.stanford.edu. Accessed 12 Feb 2017

8. PTC Inc., http://www.ptc.com/internet-of-things. Accessed 12 Feb 2017

9. Donaldson, Krista, M., Ishii, K., Sheri, D., Sheppard: Customer Value Chain Analysis. Research in Engineering Design16.4, 174-183 (2006)

10. Ministry of Education, Culture, Sports, Science and Technology (MECSST), http://www.mext.go.jp/a_menu/shinkou/sangaku/1347910.htm. Accessed 12 Feb 2017

11. Yoshie, O., Wang, L.: Building hub for global human resource development and lessons learned from it, Waseda Institute of Political Economy Working Paper Series No.E1520 (2016)

12. 2X2 Matrix, https://dschool-old.stanford.edu/groups/k12/wiki/29e5a/2X2_Matrix.html. Accessed 31 Mar 2017 